\title{
O CONHECIMENTO A SERVIÇO DA FÉ: NOÇÕES DE CIÊNCIA NA REVISTA VOZES DE PETRÓPOLIS (1907 A 1917)1
}

\author{
Isabel Bilhão* \\ lattes.cnpq.br/9411371632646979
}

\begin{abstract}
Resumo: Nas décadas iniciais do século XX, diante da laicização do ensino público, do avanço de correntes racionalistas e anticlericais e de novas religiões no país, a Igreja Católica precisou enfrentar uma inusitada concorrência na arena educacional. A imprensa tornou-se uma importante arma de combate, largamente utilizada tanto por membros do clero, quanto por seus opositores. O artigo analisa um dos veículos participantes desse confronto: a Revista Vozes de Petrópolis. O periódico, fundado por freis franciscanos em 1907, propunha-se a colaborar para a formação de uma intelectualidade católica que pudesse responder aos desafios de seu tempo, especialmente através de artigos relacionados à ciência e à cultura. Com base na análise de excertos de textos publicados entre 1907 e 1917, objetiva-se identificar as concepções de ciência apresentadas na Revista e as estratégias argumentativas utilizadas pelos redatores, bem como observar as redes de relações em que estes estavam inseridos e suas possíveis influências na legitimação e circulação do periódico. Pretende-se, assim, contribuir para o alargamento das reflexões acerca da participação da imprensa católica nos embates em torno da definição e difusão do conhecimento científico no país nos primórdios do século XX.
\end{abstract}

Palavras-chave: Imprensa católica; Difusão do conhecimento; Embates educacionais.

\section{KNOWLEDGE AT THE SERVICE OF FAITH: NOTIONS OF SCIENCE IN REVISTA VOZES DE PETRÓPOLIS (1907 A 1917)}

\footnotetext{
${ }^{1}$ Discussão realizada no âmbito do projeto de pesquisa "Entre a fé e a razão: disputas de católicos e anarquistas pela educação operária (Espanha, Brasil e Argentina, 1891 a 1920)", desenvolvido com financiamento do Edital Universal do CNPq no Programa de Pòs-Graduação em Educação da Universidade do Vale do Rio dos Sinos. Uma versão preliminar desse texto foi aprovada no IX Congresso Brasileiro de História da Educação.

* Doutora em História. Docente na Universidade do Vale do Rio dos Sinos, Unisinos (Brasil). Contato: iabilhao@gmail.com.
} 


\begin{abstract}
In the early decades of the twentieth century, due to the laicization of public education, the advance of rationalist and anticlerical currents and new religions in the country, The Catholic Church had to face an unusual competition in the educational arena. The press has become an important weapon of combat, much used by members of the clergy and their opponents. The article analyzes one of the vehicles participating in this confrontation: the Revista Vozes de Petrópolis. The periodical, founded by Franciscan friars in 1907, aimed at collaborating in the formation of Catholic intellectuals who could respond to the challenges of their time, especially by means of articles related to science and culture. Based on texts published between 1907 and 1917, we intend to identify the conceptions of science presented in the journal and the argumentative strategies used by the editors, as well as to observe the networks of relations in which they were inserted and their possible influences on the legitimacy and circulation of the periodical. The intention is to contribute to the reflection on the participation of the Catholic press in the struggles around the definition and diffusion of scientific knowledge in the country in the early twentieth century.
\end{abstract}

Keywords: Catholic press; Diffusion of knowledge; Educational struggles.

$$
* * *
$$

\title{
Introdução
}

O projeto de difusão de uma imprensa católica no Brasil remonta ao período imperial, contudo, com o advento da República esta questão tronou-se premente. Em um contexto de novos tensionamentos e concorrências em âmbito religioso, político, científico e educacional, a imprensa tornou-se uma importante arma de combate, largamente utilizada tanto por membros do clero quanto por seus opositores. O enfrentamento a novas formas de disputa, que procuravam colocar em xeque a condição da Igreja de "consciência moral do mundo" (SOUZA, 2002, p. 37) e a oposição às concepções laicizantes de ensino público, tornaram imperativa a implantação de "uma imprensa católica inspirada em estratégias organizacionais modernas de propaganda e distribuição de produtos, bem como preocupada em estabelecer conceitos e políticas que definissem um mundo social edificado sob fundamento católico" (GONÇALVES, 2008, p. 65). 
Em março de 1890 o episcopado católico reconheceu oficialmente essa necessidade e apresentou, em sua primeira Pastoral Coletiva, um texto encorajando os religiosos e leigos atuantes a se lançarem na criação da "boa imprensa" que viria contrapor-se aos "estragos da imprensa ímpia” (PASTORAL COLETIVA, 1890, p. 75). Neste artigo analisa-se a atuação de um dos veículos que respondeu a esse chamado: a Revista Vozes de Petrópolis, publicação "mensal, religiosa, científica e literária”2, criada por freis franciscanos em 1907, objetivando-se identificar as concepções de ciência apresentadas na Revista e apontar as estratégias argumentativas e os mecanismos de legitimação utilizados por seus redatores. Será observada também a participação desse veículo nos embates em torno da constituição e disseminação do conhecimento científico no país.

A apresentação dessa análise está organizada em três tópicos. No primeiro, realiza-se uma breve contextualização do panorama sócio educacional brasileiro no qual se inserem os textos do periódico em estudo. O segundo apresenta as circunstâncias de criação da Revista e suas principais características editoriais. No último tópico, analisam-se concepções pedagógicas e de conhecimento científico com base em alguns excertos de textos publicados entre 1907, ano de sua fundação, e 1917, quando seu primeiro diretor deixou o cargo, encerrando-se assim um ciclo de intensas polêmicas travadas em suas páginas.

\section{Os primórdios da República brasileira: um contexto de confrontos}

Nas décadas finais do século XIX e princípios do século XX a Igreja Católica defrontou-se com a expansão de grupos de variadas correntes de militância científica, política e social que defendiam concepções racionalistas e anticlericais e se utilizavam tanto da imprensa quanto da escola para difundirem suas ideias. Em linhas gerais, o racionalismo é uma cor-

\footnotetext{
${ }^{2} \mathrm{~A}$ grafia dos textos originais das fontes foi atualizada.
} 


\section{Revista de História e \\ Historiografia da Educação}

rente de pensamento que afirma que tudo o que existe tem uma causa inteligível, mesmo que essa causa não possa ser demonstrada empiricamente. Baseia-se no uso da razão para operar conceitos, abstrações, resolver problemas e elaborar explicações de causa e efeito. Já o anticlericalismo pode ser definido tanto como a atitude de oposição ao poder temporal da Igreja, especialmente relacionado aos abusos políticos e econômicos por ela cometidos em diferentes contextos, quanto como a hostilidade ao catolicismo como religião ou ideologia (RIEGELHAUPT, 1982, p. 1216).

No Brasil tal confronto também poderia ser observado, e grupos anarquistas, socialistas, positivistas - que divergiam em muitos aspectos relacionados às concepções e formas de atuação - tendiam a encontrar no anticlericalismo, no racionalismo e na defesa da instrução importantes pontos de convergência. Some-se a isso o fato de que com a separação Estado-Igreja, advinda com a República, o catolicismo deixou de ser a religião oficial do país, expandiram-se novos credos, especialmente os protestantes, e ampliou-se a concorrência também no campo religioso. A esses confrontos agregou-se ainda a ameaça representada pela laicização do ensino público, também decorrente da instauração do novo regime, a qual representou uma evidentemente limitação da atuação católica no interior da incipinte rede escolar em formação no país 3 .

Entretanto, deve-se notar que, liberada das obrigações e do controle do poder temporal, a Igreja Católica no Brasil pôde então aprofundar seu movimento de romanização, caracterizado pela restauração das ordens religiosas, que se encontravam quase extintas no país, e pelo fortalecimento da hierarquia eclesiástica, tendo na obediência e na afirmação da infalibilidade papal seus pontos culminantes (AZZI, 1977). A romanização representava um dos lados da moeda cuja outra face era o ultramontanismo4, pelo qual, desde a publicação, em 1846, da encíclica Qui pluribus (sobre os erros

3 A Constituição Federal de 1891, em seu artigo 72, § $6^{\circ}$, definiu que seria "leigo o ensino ministrado nos estabelecimentos públicos".

4 Ultramontanismo se refere ao movimento da Igreja Católica Romana que, no século XIX, se opôs à descentralização e à nacionalização do catolicismo, defendendo a centralização hierárquica na Cúria Romana e a infalibilidade papal. 
contemporâneos e o modo de os combater), a Igreja manifestava-se contra as concepções racionalistas e anticlericais e aprofundava a ofensiva católica ao ensino laico (SOUZA, 2000). Diante disso, passou-se a valorizar o sacerdote "reformado", ou seja, com formação adequada às demandas do período e, ao mesmo tempo, obediente à ordenação e hierarquização das relações no interior do catolicismo.

Tal contexto tornou necessário renovar as velhas ordens religiosas e enviar a diferentes países novas congregações que pudessem estabelecer vínculos mais sólidos com a Cúria Romana (SOUZA, 2000). No final do século XIX chegaram ao Brasil muitos religiosos em fase de formação ou recentemente ordenados, cujas funções não se restringiriam mais à vida contemplativa, no interior de suas ordens; pelo contrário, passaram a se envolver em obras assistenciais, educativas e a incentivar e participar de associações operárias católicas (DALLABRIDA, 2005).

Esse é o caso do grupo de freis franciscanos alemães que, chegados nos anos 1890, estabeleceram, na cidade de Petrópolis/RJ, a Escola Gratuita São José, a qual ensejou, em 1901, a criação de uma oficina tipográfica que, por sua vez, permitiu a publicação, a partir de 1907, da Revista Vozes de Petrópolis. A criação dessa Revista exemplifica uma importante tensão no interior do catolicismo, pois se, por um lado, a Igreja vinha, de longa data, combatendo as concepções racionalistas, cientificistas e anticlericais e apontando-as como as principais inimigas da doutrina e da fé católicas (DENZINGER, 2007), por outro lado, tornou-se impossível menosprezar a importância do conhecimento científico, bem como deixar de dotar as famílias de instrução e argumentos que lhes possibilitassem melhor resistir tanto aos apelos de ideologias rivais quanto aos excessos laicizantes do Estado.

Naquela conjuntura, conforme interpretação de Manuel Linda, o crescente pluralismo científico, social e político motivou "a necessidade de insistência na educação [pois], da parte da Igreja havia que fazer não só com que os seus fiéis não perdessem a sua identidade específica para não se dissolverem na massa, mas até que participassem ativamente na sociedade para a recristianizar" (LINDA, 2006, p. 393). Nessa acirrada disputa, o principal meio de divulgação do pensamento católico, assim 
como das demais formas de militância político-social e de divulgação científica do período, era a publicação de jornais e revistas.

Os variados grupos editores que começavam a se disseminar pelas principais cidades do país foram beneficiados pelas novas técnicas de impressão e reprodução, pela ampliação do número de tipografias e pelo desenvolvimento paulatino dos meios de transporte que permitiram maior eficiência na entrega dos materiais (LUCA, 2008, p. 137). Entretanto, deve-se ponderar que o alargamento da produção e da circulação dos impressos não era garantia de uma correlação direta com o crescimento do número de leitores. O contexto brasileiro das décadas iniciais do século XX apresentava uma difícil realidade, a de que aproximadamente $85 \%$ da população do país era analfabeta (PAIVA, 1973, p. 70). Tal dado permite avaliar os grandes obstáculos enfrentados na divulgação de textos escritos. Logo, não se pode estranhar o fato de que muitos indivíduos ou grupos se engajassem igualmente em projetos editoriais e educacionais e que vivessem sua militância literária em conexão com a luta pela ampliação da escolarização5. Essa situação também foi vivida pelo grupo editor da Revista Vozes, uma vez que boa parte de seus colaboradores também participava da escola franciscana de Petrópolis.

Porém, a dificuldade representada pelo analfabetismo não deve ser vista nem como uma exclusividade nacional, nem como um fator de impedimento absoluto do acesso à informação impressa, pois existem inúmeras evidências de que no Brasil, de forma semelhante ao que ocorria em outros países, realizava-se a prática conhecida como leitura extensiva. Esse procedimento permitia, especialmente aos moradores dos centros urbanos, o acesso a textos variados que, lidos em voz alta e discutidos coletivamente, eram interpretados e apropriados pelos leitores. Estes podiam até mesmo atribuir-lhes significados distantes dos pretendidos pelos autores, mas, gradualmente, se familiarizavam com os impressos e passavam a naturalizar o texto escrito como forma, por excelência, de difusão de informações e conhecimentos. Nesse contexto deve-se compreender a criação da Revista Vozes de Petrópolis, da qual se tratará a seguir.

5 Uma análise dessa militância intelectual é feita por Nicolau Sevcenko (2003). 


\section{Vozes de Petrópolis, uma breve apresentação}

Como referido, a Revista Vozes de Petrópolis foi criada em $1^{\circ}$ de julho de 1907, por um grupo de freis franciscanos alemães que havia chegado ao país no final do século XIX. Entretanto, sua publicação decorreu de um processo mais longo, antecedido pelo estabelecimento, em março de 1901, da Tipografia da Escola Gratuita São José, responsável pela composição e impressão dos livros utilizados na escola e que servia também como espaço de formação prática para os alunos aprendizes de tipografia (ANDRADES, 2001; NEOTTI, 2007).

Uma das características marcantes do percurso da Revista foi a longevidade, excepcional para os padrões nacionais. Suas atividades foram encerradas em 2003, após 96 anos de existência. Ao longo desse período a publicação passou por diferentes fases e orientações editoriais, que levaram inclusive a modificações em seu nome. Frei Clarêncio Neotti, seu diretor de 1966 a 1987, em uma homenagem póstuma assinalou que, em 1942, a Revista passou a designar-se Vozes - Revista Católica de Cultura, denominação utilizada até 1969, quando passou a se chamar Revista de Cultura Vozes, nomenclatura mantida até 1993, quando mudou para Cultura Vozes, designação que perdurou ao longo de sua última década de circulação (NEOTTI, 2007).

Em suas fases mais contemporâneas, a Revista Vozes já serviu de base empírica a estudos acadêmicos como o de Assis (2008), tratando de sua concepção de educação durante os debates da LDB (1956 a 1965), e o de Andreo (2015), que realiza uma análise comparativa entre a Vozes e a Revista Christus, do México, enfocando a reorientação católica pós Concílio Vaticano II e as relações de ambas publicações com a Teologia da Libertação, no período de 1966 a $1980^{6}$. Em relação ao período de funda-

\footnotetext{
6 O Concílio Vaticano II (XXI Concílio Ecumênico da Igreja Católica), foi convocado em 25 de dezembro de 1961, pelo Papa João XXIII e inaugurado em 11 de outubro de 1962. Realizou-se em quatro sessões, das quais participaram mais de dois mil prelados. Concluído em 8 de dezembro de 1965, já sob o papado de Paulo VI, esse concílio
} 
ção e anos iniciais do periódico não foram encontrados estudos acadêmicos específicos. Cabe mencionar, entretanto, a tese de Claudio Aguiar Almeida (2002) que discute a utilização da imprensa, cinema e outros meios de comunicação por parte de grupos católicos ligados à Ordem Franciscana no período de 1907 e 1937 observando, entre outros periódicos, a Revista Vozes.

A criação da Revista atendeu à necessidade de publicação de um periódico que tanto pudesse servir como "arma de combate" para a afirmação dos ideais religiosos, diante da laicização do ensino público e da expansão de variados grupos racionalistas e anticlericais, quanto apresentasse à comunidade católica uma visão de ciência, cultura e conhecimento que não estivesse em contradição com a fé, ou melhor, que fosse subordinada à fé. A Vozes de Petrópolis tornou-se, assim, um veículo de formação que buscava oferecer às famílias, professores e estudantes das escolas católicas, alternativas de informação e conhecimento, procurando evitar que esses recorressem às leituras não recomendadas ou aos textos de antagonistas.

Quanto à escolha do nome, a memória institucional da Editora Vozes apresenta a seguinte explicação: “A tipografia da Escola [São José] decide criar uma revista católica de cultura. Frei Ambrósio, na época assinante do jornal alemão Stimmen der Zeit (Vozes do Tempo), sugeriu Vozes de Petrópolis, que foi aceito"7. Aparentemente o sucesso da publicação acabou por renomear o empreendimento que lhe deu origem, já que, em 1911, a tipografia da Escola Gratuita São José passou a ser

discutiu e regulamentou vários temas relacionados ao aggiornamento (atualização) das relações da Igreja Católica com o mundo moderno. A Teologia da Libertação é uma corrente teológica cristã surgida na América Latina após o Concílio Vaticano II e da Conferência de Medellín (Colômbia, 1968). Tem como um de seus marcos temporais a publicação, em 1971, do livro $A$ Teologia da Libertação, de autoria do padre peruano Gustavo Gutiérrez. Esse movimento parte da premissa de que o Evangelho exige a "opção preferencial pelos pobres" e engloba várias correntes de pensamento que interpretam os ensinamentos de Jesus Cristo em termos de uma libertação de injustas condições econômicas, políticas ou sociais.

7 Disponível em http://www.universovozes.com.br/editoravozes/web/view/Historia 1900.aspx. Acesso em: 10 mar. 2017. 
chamada de Administração da Vozes de Petrópolis e, mais tarde, de Editora Vozes de Petrópolis (ANDRADES, 2001; NEOTTI, 2007).

No grupo de editores da Revista, destacava-se naquele período a figura de Frei Pedro Sinzig. Chegado da Alemanha, ainda noviço, em 1893, depois de algumas andanças pelo Brasil fixou-se na cidade de Petrópolis, e ali dirigiu, entre 1908 e 1913, a tipografia mantida por sua congregação e editou a Revista Vozes até 1917. Por meio dela publicou grande quantidade de artigos assinados ou sob pseudônimos e travou calorosas polêmicas com aqueles que, a seu ver, ameaçavam a "boa imprensa”. Boa Imprensa, aliás, foi o nome de um centro por ele fundado em 1910, com a finalidade de reunir e incentivar veículos da imprensa católica e propagar o que a seu ver seria a sã leitura, tal como havia determinado a "Pastoral Coletiva" de 1890 (ANDRADES, 2001; SANTOS, 2006; ASSIS, 2008).

Além disso, Frei Pedro promoveu a modernização da gráfica, que já produzia materiais didáticos para a Escola Gratuita São José, e tornou-a fornecedora de várias outras escolas católicas brasileiras. O religioso, dotado de verve polemista e militante, também escreveu uma grande quantidade de obras (romances, contos e novelas) de caráter doutrinário, tornando-se mais conhecido nos meios literários por seu livro Através dos Romances: Guia para as consciências, de 1915, no qual estabelecia uma classificação crítica para as obras literárias em circulação no período, qualificando-as como: sadias, com ressalvas e proibidas, visando orientar a leitura das famílias católicas ${ }^{8}$.

De sua fundação até a década de 1990 a Revista manteve praticamente inalterado seu formato, americano, medindo $14 \times 21 \mathrm{~cm}$, e apresentando de 70 a 100 páginas, divididas em mais ou menos 20 artigos, mantendo a periodicidade mensal. A Vozes tornou-se rapidamente um sucesso editorial, em 1910 "a revista contava com 1700 assinaturas, fora as vendas avulsas. Seus artigos eram transcritos em diversos jornais e re-

\footnotetext{
8 Na primeira edição do Guia, em 1915, Frei Pedro apresentava a crítica de 11.863 livros e 5.150 autores. Na edição revista e ampliada, de 1923, seriam classificados 21.553 livros e 6.657 autores. Tamanho esforço doutrinário fez com que o religioso fosse considerado um dos principais censores católicos do século XX. Sobre a questão ver: Paiva (1997) e Carneiro (2002).
} 
vistas pelo Brasil” (ASSIS, 2008, p. 26,). Pode-se, contudo, ponderar que, no período em análise, o crescimento da Editora, conjuntamente com o da Revista, também se deveu às boas relações dos freis com políticos, autoridades e parte da intelectualidade da elite nacional. A Revista mantinha entre seus colaboradores o Conde Afonso Celso, herdeiro da política imperial e um dos membros fundadores da Academia Brasileira de Letras; o Deputado João Hosannah de Oliveira e o Ministro Viveiros de Castro, entre outros.

O periódico, entretanto, enfrentou um grande revés durante a Primeira Guerra Mundial, quando a verve de seu diretor extrapolou os limites aceitáveis pela maioria dos assinantes. Frei Pedro Sinzig, envolveu-se, em 1917, em uma polêmica após a publicação de alguns artigos em defesa da Alemanha, fazendo com que a ofensa ao espírito nacionalista dos leitores resultasse no cancelamento de assinaturas. Além disso, a exemplo do que ocorria em outras cidades brasileiras, alguns populares de Petrópolis promoveram, no mesmo ano, saques e quebraquebras a empresas e lojas de estrangeiros. A Editora Vozes também foi depredada e acabou por suspender temporariamente suas atividades e afastar Sinzig da direção da Revista (ANDRADES, 2001; ASSIS, 2008). Em 1919 o religioso retornou à Alemanha, onde permaneceu até 1922. Quando voltou ao Brasil ficou morando em "Fortaleza e Salvador onde continuou com atividades literárias, musicais e jornalísticas. De volta ao Rio, fundou, em 1940, a revista Música Sacra, publicada pela Editora Vozes" (ANDRADES, 2001, p. 34)9.

No próximo tópico serão abordados as principais concepções de conhecimento científico publicadas nos primeiros anos de circulação da Revista que, em seu editorial de estréia, prometia "não excluir do programa nenhuma região da ciência e da técnica, da teoria e da prática" (Vozes de Petrópolis, Ano I, 1907/o8, p. 1).

9 Sinzig dirigiu essa revista até o ano de seu falecimento, 1952. 


\section{Vozes de Petrópolis:}

\section{uma revista de combate}

Nesse tópico se buscará analisar, com base em excertos, alguns aspectos da difusão de ideias encetada pela Revista Vozes de Petrópolis. Entretanto, antes de iniciarmos essa reflexão fazem-se necessárias algumas ponderações de caráter teórico e metodológico. A primeira delas diz respeito ao fato de que essa Revista é um instrumento de difusão do pensamento de homens da Igreja. Mas, como observou Émile Poulat, a Igreja é um típico caso de "conflito no consenso ou de consenso no conflito" (2002, p. 15), pois nela se entrecruzam diferentes e, muitas vezes, antagônicas tendências, envolvidas diretamente com as realidades mais amplas nas quais tanto a instituição, enquanto estrutura hierárquica, quanto seus agentes leigos ou religiosos, estão inseridos.

Tal constatação permite vislumbrar o quão complexa pode se tornar a tarefa de estudar algum aspecto de sua ação, uma vez que não se deve esperar dessa, ou de qualquer outra instituição, alguma coerência inata ou unidade monolítica de seus agentes. Exemplo disso são os conflitos gerados pelos artigos de Pedro Sinzig, acima mencionados, que não apenas desagradaram leitores leigos, como podem ter agravado confrontos de opiniões com o grupo de religiosos, levando ao seu afastamento da Revista.

Outra consideração diz respeito ao fato de que, como ponderou Robert Darnton (1996, p. 15), os veículos de imprensa, enquanto força ativa na vida moderna, devem ser pensados mais "como integrantes dinâmicos do processo de construção do que de registro dos acontecimentos, atuando na concepção e construção de nossos modos de vida, perspectivas e consciência histórica”. Todavia, não basta apontar, como observam Heloisa Cruz e Maria Peixoto, que a imprensa e as mídias em geral "têm uma opinião". Fundamental é perceber que

[...] em sua atuação delimitam espaços, demarcam temas, mobilizam opiniões, constituem adesões e consensos. Mais ainda, trata-se também de entender que em diferentes conjunturas a 
imprensa não só assimila interesses e projetos de diferentes forças sociais, mas muito frequentemente é, ela mesma, espaço privilegiado da articulação desses projetos. (CRUZ; PEIXOTO, 2007, p. 258-259).

Se essa constatação pode ser realizada para a imprensa em geral, muito mais contundente é o caso de veículos como a Revista em pauta, criados para servir de "arma" em confrontos de ideias. A análise desses impressos deve considerar ainda que "numerosos textos têm por objetivo anularem-se enquanto discurso e produzir na prática comportamentos ou condutas tidos por legítimos e úteis" (CHARTIER, 2002, p. 135), ou seja, "naturalizarem-se" frente aos leitores.

Com isso, chega-se a outro fator importante, assinalado por John Pocock: a necessidade de nos ocuparmos da reconstituição do sentido histórico das ideias. Ou seja, de recuperarmos "as intenções dos textos estudados a partir da análise do contexto histórico em que foram produzidos, levando-se também em consideração os eventos e os debates travados frente às questões formuladas por outros grupos" (POCOCK, 2003, p 33). Nessa linha argumentativa, Quentin Skinner ressaltou o fato de que, quando escreve, o autor não se limita a emitir enunciados, mas, por meio de seus "atos de fala, discute, interpela ou responde a outros, decorrendo disso a necessidade de sua contextualização rigorosa" (SKINNER, 1999, p. 21).

A abordagem metodológica desse estudo procurou observar essas advertências. Para tanto foram seguidos três procedimentos: inicialmente realizou-se a seleção dos excertos com base nos assuntos veiculados, priorizando-se aqueles que remetiam às noções de ciência e conhecimento apresentadas ao longo da primeira década de circulação do periódico. Em seguida procedeu-se a análise textual, observando-se: os enunciados explícitos e as mensagens nas entrelinhas; as teses defendidas, as denúncias e acusações formuladas, o uso de "falas de autoridade”, pensadas em suas possíveis relações com o contexto histórico e com os embates nos quais a Revista se envolvia. O terceiro procedimento procurou observar as redes de relações das quais participavam os autores e o grupo editor, visando compreender seus possíveis 
impactos na consolidação, disseminação e influência do periódico junto aos leitores.

O primeiro editorial da Revista fornece interessantes indícios de análise. Entre os objetivos da nova publicação, estão:

[...] oferecer ao povo, por preço módico, uma leitura civilizadora e moralizadora, de artigos variados e de interesse geral [...]; cumprir um imperioso dever religioso-social, que tanto mais se impõe quanto mais atrevida se torna, em nossos dias, a inundação de más leituras, que tão grande perigo constituem para a Igreja e o Estado. (Revista Vozes de Petrópolis, Ano I, 1907/o8, p. 1).

Nesse trecho se pode observar tanto uma intenção iluminista, "civilizadora e moralizadora", marcante no discurso educacional em construção no período - que atribuía ao conhecimento o poder de modificar os seres humanos, associando maldade à ignorância e bondade a conhecimento - quanto o reconhecimento de que, com "a inundação de más leituras" o campo educacional se encontrava em disputa, não apenas o escolar, mas principalmente aquele que dizia respeito à construção de uma "consciência moral do mundo". Dessa forma, o combate aos "erros modernos", anteriormente aludidos, tornava-se uma necessidade premente e os homens da Igreja, em seus grupos variados e heterogêneos, lançaram mão das armas disponíveis no período. No caso em questão, um veículo de imprensa que procuraria

Contrabalancear, não por meio de polêmicas infrutíferas, mas por meio de artigos positivos dos diversos ramos dos conhecimentos humanos, as impressões funestas deixadas em toda a parte pelos porta-bandeiras deste movimento anti-religioso e anti-social, que visa unicamente estabelecer uma antítese artificial, inexistente entre a fé e a ciência [...]. (Revista Vozes de Petrópolis, Ano I, 1907/08, p. 1).

Ao se lançarem na empreitada de criação da Revista, seus idealizadores mostravam disposição de combater no terreno do "inimigo". Em seu primeiro editorial a Revista Vozes aborda a questão da seguinte maneira: 
Os progressos da arte tipográfica que, sobretudo, deviam servir para propagar as ideias sensatas e multiplicar os frutos da virtude têm sido aproveitados para o mal e se têm aumentado, quase ao infinito, os órgãos do vício, os quais sufocam os germes do bem e lançam no seio da inocência e do pudor a semente venenosa do pecado. (Revista Vozes de Petrópolis, Ano I, 1907/o8, p. 2).

Nessa passagem os redatores reconhecem o processo irrefreável de difusão e circulação de ideias e conhecimentos que, partindo dos mais variados quadrantes, espalhavam-se pela sociedade e ensejavam novas leituras de mundo, as quais muitas vezes o poder católico já não conseguia regular. $\mathrm{O}$ trecho abaixo discute essa questão apoiando-se em uma importante "fala de autoridade", o discurso "Le vie nuove del Clero" (Novas formas de Clero), proferido pelo Cardeal Capecelatro, em 3 de Maio de 1907:

Os erros no terreno religioso, filosófico e moral, observa o cardeal Capecelatro, que antes se debatiam nos mais altos cumes do saber, entre gênios eleitos e os homens doutos, agora, pelos caminhos literários, desceram, por assim dizer, às planícies e aos vales por onde penetram facilmente nos ânimos das multidões. (Revista Vozes de Petrópolis, Ano I, 1907/o8, p. 2).

Logo, tornou-se impossível para a Igreja ignorar a importância e o impacto da difusão de conhecimentos entre os leigos. Os franciscanos de Petrópolis, conhecedores dos movimentos de renovação de setores da hierarquia católica na virada do século XIX para o XX, ao apoiarem-se no discurso do Cardeal Capecelatro, arcebispo de Cápua, apontavam para uma postura condizente com as noções do que ficou conhecido como "catolicismo liberal”, ou seja, um movimento que, segundo Giacomo Martina, procurava defender "o primado da consciência, a conciliação entre autoridade e liberdade, a autonomia da ciência, a libertação das estruturas eclesiásticas supérfluas, a renovação do culto" (MARTINA, 1997, p. 75-76). Contudo, tais tendências modernizantes não significavam o abandono de antigas concepções, bastante arraigadas tanto no pensamento religioso quanto no anticlerical, de que as multidões não poderiam 
ser deixadas sem guia, devido a sua incapacidade de bem compreender o que antes se debatia apenas "nos cumes do saber".

O editorial terminava com a já mencionada promessa de que "a $V o$ zes de Petrópolis terá caráter geral e não puramente religioso. Trará a nossa revista artigos variados que terão o cunho da atualidade. Nenhuma região da ciência e da técnica, da teoria e da prática será excluída do programa. Eis ai o nosso Quo Vadis" (Revista Vozes de Petrópolis, Ano I, 1907/o8, p. 2).

Uma das estratégias utilizadas pela Revista na missão de apresentar a ciência sem distanciá-la da fé foi destacar exemplos de cientistas que, tendo efetivamente colaborado para o avanço de suas áreas de conhecimento, mantiveram-se crentes. Um dos primeiro homenageados foi Louis Pasteur. Segundo o texto:

Esse homem que lutou vitoriosamente contra a moléstia e a morte, esse homem que eliminou da superfície da Terra medonhos flagelos, cuja lembrança ainda nos enchem de terror, que fez calar gritos seculares de dor, esse homem que tem poupado milhares e milhares de vidas até então fatalmente condenadas, era um crente e um crente fervoroso. Nunca se envaideceu com seus triunfos deslumbrantes, nunca pretendeu organizar cientificamente a humanidade e nem organizar a Deus. (Revista Vozes de Petrópolis, Ano I, 1907/o8, p. 97).

O texto não se preocupava em tratar efetivamente dos feitos científicos do eminente retratado, explicando inclusive que "as gloriosas descobertas pasteurianas já seriam bem conhecidas" (Revista Vozes de Petrópolis, Ano I, 1907/08, p. 97). O primeiro interesse do redator - que subscreve com o pseudônimo de Ignotus (do Latim, desconhecido) parece residir na demonstração, pela via do exemplo, da inexistência de contradições entre saber e devoção. O segundo mote direcionava-se ao questionamento da noção de organização científica da sociedade, discussão bastante em voga na jovem República e que empolgava parte da intelectualidade brasileira, seguidora dos preceitos da "física social", 
de Augusto Comte ${ }^{10}$ (LEVINE, 1997).

O combate ao Positivismo, entretanto, não fazia com que os editores da Vozes se furtassem ao debate da “questão social”. Em 1908, lançaram uma longa campanha em prol do descanso dominical e propuseram uma discussão com "bases sociológicas" para o problema da organização do trabalho, defendendo que

[...] a oposição de interesses entre patrões e trabalhadores, que não é fenômeno natural, nada tem, entretanto, em nossos dias, de acidental; é a consequência lógica de todo o regime econômico e social; por isso, enquanto ele durar, não pode uma organização ter outro objetivo imediato que não o estabelecimento dos compromissos necessários para temperar as consequencias desse conflito. (Revista Vozes de Petrópolis, Ano II, 1908/09, p. 257).

A coluna, da qual esse trecho foi retirado, perdurou por várias edições da Revista. O objetivo era apresentar o "Catolicismo Social" aos leitores. Tal discussão insere-se em um contexto mais amplo de transformações no interior da Igreja, especialmente a partir da publicação da encíclica Rerum Novarum ${ }^{11}$, durante o pontificado de Leão XIII (1878-1903). Naquele momento a hierarquia Católica precisou reconhecer a existência de uma "questão social" e tratá-la como um problema estrutural, inerente à lógica capitalista.

Ao discutir a "questão social", vários setores católicos passaram, por um lado, a empregar o vocabulário sociológico, reconhecendo as relações entre organização econômica, exploração do trabalho e remuneração do capital. Por outro lado, ao debruçar-se sobre essas questões a Igreja tentou não apenas recuperar o espaço perdido com a expansão das ideias liberais, socialistas e anarquistas, mas também se firmar como instituição normalizadora da lógica social que se estabelecia, definindo pa-

10 O pensador francês, combatido na Revista, procurou organizar as premissas da sociologia positivista para o estudo dos fenômenos sociais com base nos mesmos preceitos de análise dos fenômenos físicos, astronômicos, químicos e fisológicos.

${ }^{11}$ Editada em maio de 1891, em linhas gerais reforçava o direito à propriedade privada e a necessidade de harmonia entre as classes sociais, condenava as idéias socialistas e anarquistas e apontava o corporativismo como forma de resolução dos problemas sociais. 
drões de comportamento aceitáveis tanto para os trabalhadores quanto para os patrões.

Em âmbito local, a equipe editorial da Revista Vozes procurou participar ativamente desse processo, dentre outras maneiras, questionando a ação de militantes anarquistas na cidade e colocando-se frontalmente contra sua estratégia grevista. No seguinte trecho, retirado de um texto assinado por Pedro Sinzig observa-se um exemplo dessa conduta: "os anarquistas vos pregam, levianamente, a greve. Ora, aparecem eles para conseguir-vos um novo emprego quando demitidos? [...] Eles nunca foram vistos nos escritórios dos patrões, para falarem por vós, enquanto mais de cem de vossos camaradas deve sua readmissão na fábrica a meus confrades de sacerdócio" (Vozes de Petrópolis, Ano 6, 1º11/1913).

Como o compromisso fundante da Revista era não excluir do programa nenhuma região da ciência ou da técnica, não deve causar admiração que a Biologia e os conhecimentos da fisiologia humana também fossem mencionados. Ao longo de vários anos foi publicada a coluna Sciencia e Religião. Nela os leitores encontravam informações sobre as mais variadas descobertas relacionadas a esse campo do conhecimento, apresentadas sempre de forma subordinada à explicação religiosa. Um exemplo nesse sentido é o texto sobre as inovadoras descobertas realizadas pelo neurologista francês Pierre Marie, em relação ao funcionamento do cérebro humano. $\mathrm{O}$ artigo, assinado novamente por Ignotus, buscava apresentar, em tom didático, as correlações entre as funções dos lobos occipitais e os estímulos visuais. Para os fins da presente análise, interessa mais o desfecho do texto no qual o articulista conclui que, a despeito de todas as teorias materialistas então em voga, o que realmente explicaria o mistério do funcionamento cerebral, seria a existência da

Alma, que anima todo nosso ser que adquire a consciência da sensação, no cérebro, ao mesmo tempo em que recebe a impressão do objeto no órgão do sentido, e o ato sensível operase imediatamente [...]. Tal é o mecanismo simples e harmonioso da sensibilidade. Pela sua singeleza, ele atordoa a nossa pobre ciência e ao mesmo tempo nos faz curvar cheios de admiração e respeito diante dessa maravilha, onde claramente se revela a 
mão do criador. (Revista Vozes de Petrópolis, Ano III, 1909/10, p. 690-691).

Esse trecho permite sintetizar muito do que se vem tentando explicar nesse artigo. Ele enseja, por um lado, perceber o esforço realizado pela equipe editorial para manter-se atualizada com as discussões científicas de seu tempo. Tal esforço demandava tanto a manutenção de correspondência com centros europeus, na busca de textos de divulgação de conhecimentos, quanto o empenho na tradução desses materiais e na didatização das explicações oferecidas aos leitores. Por outro lado, os trechos assinalados apontam para a importante missão do periódico em sua primeira década de circulação, a de subordinar os prodígios da ciência, reconhecidos em suas páginas, à fé e à religião.

Além disso, os textos publicados esforçavam-se para propagandear as vitórias da Igreja Católica em outros âmbitos. O artigo intitulado "A Igreja no Brasil de Pio X" apresenta um balanço da situação da Igreja Católica no país nas duas primeiras décadas republicanas. O tom é otimista e a argumentação demonstra o fortalecimento da instituição, a despeito da laicização oficial do Estado. Segundo o texto,

De certo tempo a esta época temos visto que em todas as classes da sociedade os homens, desvencilhados de antigos preconceitos e de receios inexplicáveis, com uma prática louvável das regras e preceitos vão atestando claramente a fé católica, já no parlamento, já no governo, já em associações, já na preferência que mostram pelos estabelecimentos de ensino que religiosos dirigem...". (Revista Vozes de Petrópolis, Ano IV, 1910/11, p. 791).

É interessante perceber que, entre os exemplos da afirmação da Igreja, estavam os procedimentos de homens públicos em órgãos executivos e legislativos que em suas rotinas ignoravam a separação EstadoIgreja. Tal descrição, evidentemente pode ser vista mais como um recurso propagandístico de defesa da reconquista de espaços do que como prática corrente no novo regime. Por outro lado, é inegável que existiam, de fato, exemplos de avanços de concepções e símbolos católicos sobre algumas instituições republicanas. A Vozes de Petrópolis se encarregava de destacar tais acontecimentos. Nesse sentido, um texto intitulado "Cristo 
no Júri de Petrópolis” descreveu a solenidade de recolocação da imagem do crucifixo na sala do tribunal do júri da cidade, salientando que: "As 2 horas da tarde de domingo, 29 de junho [de 1913], a matriz de S. Pedro d'Alcantara já não comportava mais fieis: era dali que a imagem do Cristo devia seguir procissionalmente em direção ao Fórum de Petrópolis" ( $R e$ vista Vozes de Petrópolis, Ano VI, 1913/14, p. 1090). A narrativa informava ainda que o mesmo procedimento já havia sido adotado na cidade de São Paulo.

Ambas as passagens exemplificam um amplo contexto de disputas simbólicas, políticas e materiais no interior do novo regime. Para os intuitos desse artigo, entretanto, interessam mais os aspectos dos confrontos relacionados às definições e disseminações do conhecimento e, nesse caso, um dos espaços privilegiados de embate era a escola. Noberto Dallabrida (2005, p. 79) analisou a questão e observou a existência de campanhas estimulando professores católicos a prestarem concurso nas escolas públicas, visando a "combater por dentro o ensino leigo". Mas, no exemplo em pauta, podemos observar que além de buscar "recatolizar" o ensino público, uma parcela de religiosos também comemora a preferência da população pelos estabelecimentos de ensino mantidos por religiosos, questão tomada como uma prova de que as famílias optavam por educar seus filhos na fé católica. Obviamente a Revista não mencionava o fato de que na maior parte do território nacional naquele período o ensino público ainda não oferecia significativa concorrência à expansão da rede confessional. Esta última, impulsionada pela entrada de grande quantidade de ordens e religiosos no país, passou a alcançar novos setores da população, entre eles os filhos de trabalhadores urbanos.

A expansão de publicações como a Revista Vozes parece ter contribuido para a conformação e difusão de um discurso católico "esclarecido" que aos poucos alcançou diversas regiões. Com esse intuito, a Administração da Vozes organizou uma rede de distribuição contando com o apoio de bispos e vigários que viram na Editora "a solução para o problema da carência de publicações religiosas em língua portuguesa e, mais ainda, de publicações que pudessem recomendar aos fiéis, sem receio de perturbar-lhes a fé" (ANDRADES, 2001, p. 57-58). Essa rede de 
circulação permitiu ainda que o periódico se tornasse uma importante fonte de informação para professores, pais e estudantes da rede de escolas confessionais em expansão.

A guisa de conclusão, cabe destacar que os excertos aqui apresentados possibilitam a percepção da atuação de um grupo de religiosos em um momento crucial da trajetória da Igreja Católica como instituição que, assim como em outros períodos, teve que adaptar-se para sobreviver e tentar manter sua influência ideológica. Na esteira da universalização do capitalismo e da sociedade de massas, ocorrida entre os séculos XIX e $\mathrm{XX}$, novos adversários e novos desafios surgiram, obrigando a um combate mais acirrado, no qual a imprensa tornava-se crucial.

Mas, mais especificamente, a leitura dos exemplares da Revista Vozes, em sua primeira década de circulação, permite refletir sobre aspectos da história da educação e da difusão do pensamento científico no Brasil. Tratava-se, então, da reorganização do mundo do trabalho e da formação de cidadãos no novo contexto republicano, tarefas que ainda se ressentiam das marcas da escravidão, há pouco abolida, e do precário nível de instrução geral da população, inclusive de suas elites. Naquele contexto, a disputa pelos corações e mentes, travadas com diversas instituições e correntes antagônicas, forçava os redatores à elaboração de um discurso complexo que, por um lado, necessitava insistir em certos pilares da fé, fundamento da instituição, não podendo, de outra parte, deixar de abrir-se aos novos tempos, sob risco de soçobrar frente à argumentação concorrente, sobretudo a laicizante e racionalista.

\section{Referências}

ALMEIDA, C. A. Meios de comunicação católicos na construção de uma ordem autoritária 1907-1937. Tese de doutorado (História), Universidade de São Paulo, São Paulo, 2002. 
ANDRADES, M. F. (coord.). Editora Vozes: 100 anos de história. Petrópolis: Vozes, 2001.

ANDREO, I. L. Aggiornamento católico e teologia da libertação no Brasil e no México: um estudo histórico-comparativo entre a revista de Cultura Vozes e a Revista Christus (1966-1980). Tese de doutorado (História), Universidade Estadual Paulista, Assis, 2015.

ASSIS, M. P. A concepção de educação na Revista Vozes durante os debates da LDB (1956 a 1965): o período de Frei Aurélio Stulzer. Dissertação de mestrado (Educação), Pontifícia Universidade Católica de São Paulo, São Paulo, 2008.

AZZI, R. O episcopado do Brasil frente ao catolicismo popular. Petrópolis: Vozes, 1977.

CARNEIRO, M. L. T. Livros proibidos, ideias malditas: o DOPS e as minorias silenciadas. São Paulo: Ateliê editorial; PROIN/USP; FAPESP, 2002.

CARVALHO, J. M. Cidadania no Brasil: o longo caminho. Rio de Janeiro: Civilização Brasileira, 2001.

CHARTIER, R. A História Cultural entre práticas e representações. Lisboa: DIFEL, 2002.

CRUZ, H. F.; PEIXOTO, M. R. C. Na oficina do historiador: conversas sobre história e imprensa. Projeto História, São Paulo, n. 35, p. 253-270, 2007.

DALLABRIDA, N. Das escolas paroquiais às PUCs: República, catolização e escolarização. In: STEPHANOU, M.; BASTOS, M. H. C. (org.). Histórias $e$ memórias da educação no Brasil. Petrópolis: Vozes, 2005, p. 77-86.

DARNTON, R. Introdução. In: DARNTON, R.; ROCHE, D. (org.). A revolução impressa: a imprensa na França, 1775-180o. São Paulo: Edusp, 1996.

DENZINGER, H. Compêndio dos símbolos, definições e declarações da fé moral. São Paulo: Paulinas; Edições Loyola, 2007.

GONÇALVES, M. Missionários da 'boa imprensa': a revista Ave Maria e os desafios da imprensa católica nos primeiros anos de século XX. Revista Brasileira de História, v. 28, n. 55, 2008, p. 63-84.

LEVINE, D. N. Visões da tradição sociológica. Rio de Janeiro: Jorge Zahar, 1997.

LINDA, M. A educação, missão essencial da Igreja. Humanística e teologia. Universidade Católica Portuguesa, Lisboa, Tomo 27, p. 389-406, 2006.

LUCA, T. R. História dos, nos e por meio dos periódicos. In: PINSKY, C. B. (org.). Fontes históricas. São Paulo: Ed. Contexto, $2^{\mathrm{a}}$ ed., 2008.

MARTINA, G. História da Igreja: de Lutero a nossos dias (Volume IV: A era contemporânea). São Paulo: Edições Loyola, 1997.

NEOTTI, F. C. Revista Vozes: uma jovem centenária revista de cultura. Ciberteologia, Ano II, n. 14, p. 48-51, 2007.

PAIVA, A. A voz e o veto: a censura católica à leitura de romances. Belo Horizonte: Autêntica, 1997. 
PAIVA, V. P. Educação popular e educação de adultos. São Paulo: Loyola, 1973.

POCOCK, J. Linguagens do ideário político. São Paulo: Edusp, 2003.

POULAT, É. Histoire, dogme et critique dans la crise moderniste. Paris: Casterman, 2002.

RIEGELHAUPT, J. F. O significado religioso do anticlericalismo popular. Análise Social, Lisboa, vol. XVIII, p. 1213-1230, 1982.

SANTOS, M. M. Os Jardins Abençoados de um Franciscano - Discurso sobre a Leitura de Frei Pedro Sinzig: 1915-1923. Dissertação de mestrado (História Social), Universidade de São Paulo, São Paulo, 2006.

SEVCENKO, N. Literatura como missão: tensões sociais e criação cultural na Primeira República. $2^{\circ}$ ed. São Paulo: Companhia das Letras, 2003.

SKINNER, Q. Razão e retórica na filosofia de Hobbes. São Paulo: UNESP, 1999.

SOUZA, J. J. V. Círculos Operários: a Igreja Católica e o mundo do trabalho no Brasil. Rio de Janeiro: Ed. UFRJ, 2002.

SOUZA, W. D. Anarquismo, Estado e pastoral do imigrante. Das disputas ideológicas pelo imigrante aos limites da ordem: o caso Idalina. São Paulo: Ed. UNESP, 2000.

VALLADARES, E. Anarquismo e Anticlericalismo. São Paulo: Imaginário, 2000.

\section{Documentos}

Pastoral Coletiva do episcopado brasileiro ao clero e aos fiéis do Brasil. São Paulo: Typographia Jorge Seckler \& Comp., 1890.

Revista Vozes de Petrópolis, Anos I a X, 1907 a 1917.

Rerum Novarum, de Sua santidade o papa Leão XIII - sobre a condição dos operários. Rio de Janeiro: Imprensa Nacional, 1941. 